\title{
A EFETIVIDADE DA DIGNIDADE DA PESSOA HUMANA ATRAVÉS DOS DIREITOS SOCIAIS
}

\author{
THE EFFECTIVENESS OF HUMAN \\ DIGNITY THROUGH SOCIAL RIGHTS
}

\author{
Helena Liebl ${ }^{1}$
}

\section{Clóvis Demarchi}

Resumo: O presente trabalho tem como objeto tratar da efetividade do princípio da dignidade da pessoa humana, através de políticas públicas na área de direitos sociais, com isso, se pretende analisar se o princípio da dignidade da pessoa humana está sendo efetivado com a implantação de políticas públicas relacionadas aos direitos sociais no Brasil. O artigo está dividido em três tópicos, primeiro será tratado sobre os direitos sociais, sua conceituação e suas características principais, no segundo tópico, será abordado o princípio da dignidade da pessoa humana, deven- do ser estudado o conceito e características deste, bem como sua relação com os direitos sociais, por fim, será abordado como o princípio da dignidade da pessoa humana é efetivado através de políticas públicas de direitos sociais, discorrendo sobre o conceito de mínimo existencial dos direitos sociais, e o seu contra-argumento, que é a reserva do possível, bem como conceituando políticas públicas e exemplificando-as, quanto à metodologia empregou-se o método indutivo, realizado por meio da pesquisa bibliográfica e documental.

1 Advogada, membro imortal da Academia de Letras do Brasil de Santa Catarina Balneário Piçarras. Pós-graduanda em Direito Público, pela Universidade do Vale do Itajaí. Estudante do Módulo I do Curso de Preparação à Magistratura, da Escola Superior da Magistratura do Estado de Santa Catarina, membro do Grupo de Estudos Avançados em Direito Empresarial, pela Univali, com o tema Compliance. Estudante da ESMESC, extensão de Itajaí. Email: helenali.liebl@gmail.com.

2 Doutor em Ciência Jurídica pela Universidade do Vale do Itajaí, doutorado sanduíche com a Universidade do Minho, Braga - Portugal com bolsa da CAPES, mestre em Ciência Jurídica pela Universidade do Vale do Itajaí, graduação em direito pela Universidade do Vale do Itajaí (1994), graduação em fillosofia pela Faculdade de Filosofia Ciências e Letras Dom Bosco (1985), é professor titular da Universidade do Vale do Itajaí nos cursos de graduação, especialização e no Curso de mestrado em ciência jurídica. Email: demarchi@univali.br. 
Palavras-chave: Dignidade Humana. Políticas Públicas. Direitos Sociais.

Abstract: The present work has as an object to treat the principle of human dignity of the human race, through public policies, in the area of social sciences, wit it is intended to analyze the principle of human dignity of the human being is effected with the implementation of public policies related to social rights in Brazil. This article is divided into three topics, firstly it will be treated about the social leaders, its conceptualization and its main characteristics, second topic, it will be approached or the principle of human dignity of the human being, having to be studied or conceited and its characteristics, as well as its relationship with social rights, will be approached as the principle of human dignity of the human being effetivated through public policies of social rights, discording about the concept of existential minimum and or your counter-argue, that is the reservation of the possible, as analyzing public policies and exemplifying them, as methodology the authors used the inductive method, realized the work by bibliographical inquiry and documental inquiry.

Keywords: Human Dignity. Public Policies. Social Rights.

\section{INTRODUÇÃO}

O presente artigo tem como objeto discorrer sobre a efetividade do princípio da dignidade da pessoa humana consolidado por meio de políticas públicas na área de direitos sociais, de modo a analisar se tal princípio está sendo efetivado com a implantação de políticas públicas relacionadas a estes direitos.

Primeiro será estudado sobre os direitos sociais, apresentando sua conceituação doutrinária, suas características e sua disposição constitucional, depois se discorrerá sobre o princípio da dignidade da pessoa humana, abordando o seu conceito, características e relação com os direitos sociais.

Por fim, se estuda como o princípio da dignidade da pessoa humana é efetivado através dos direitos sociais, discorre-se sobre o conceito de mínimo existencial dos direitos sociais e o seu contra-argumento, que é a reserva do possível, para então, se abordar sobre políticas públicas como forma de efetivar os direitos sociais.

Quanto à metodologia empregada registra-se que tanto na 
fase de investigação como no relatório dos resultados expresso no presente trabalho se fez uso do método indutivo e no tratamento de dados se fez uso do método cartesiano. Nas diversas fases da pesquisa, foram acionadas as técnicas do referente, da categoria, do conceito operacional e da pesquisa bibliográfica.

\section{DOS DIREITOS SOCIAIS}

Os direitos sociais são aqueles que objetivam garantir aos indivíduos condições imprescindíveis para o pleno gozo dos seus direitos, e assim, demandam do Estado uma intervenção na ordem social, para que haja uma diminuição das desigualdades sociais, razão pela qual possuem um custo alto para a sua efetivação.

Destarte, a sua eficácia é, muitas vezes, limitada, já que depende de uma atuação positiva do Estado. Ademais o fato de comportar obrigações de fazer e não fazer para a sua satisfação faz com que seu reconhecimento positivo esteja longe de ser convertido em expectativas plenamente exigíveis ou em instrumentos hábeis para satisfazer as necessidades básicas. Assim, quanto a sua aplicabilidade, recentes constituições formularam o preceito de aplicabilidade imediata.

Canotilho conceitua os direitos sociais como direitos fundamentais, bem como prestações positivas que são proporcionadas pelo Estado e manifestadas em normas constitucionais, possibilitando melhores condições de vida e, portanto, são direitos que "[...] tendem a realizar a igualização de situações sociais desiguais." (CANOTILHO, 2013, p. 540).

A essencialidade dos direitos fundamentais sociais é tutelada pela constituição de 1988, tendo, portanto, grande relevância jurídica, já que contém um conteúdo mínimo existencial, sendo englobados no conteúdo jurídico do princípio da dignidade da pessoa humana. 
O dispositivo constitucional que elenca quais são os direitos sociais éo artigo $6^{\circ}$ da Constituição Federal de 1988, sendo estes, a educação, saúde, alimentação, trabalho, moradia, transporte, lazer, segurança, previdência social, proteção à maternidade e à infância e assistência aos desamparados. Ademais, são regulamentados em outros dispositivos do artigo $6^{\circ}$ a 11, bem como no Título VIII, sobre a ordem social.

Para Sarlet, o objetivo principal dos direitos fundamentais sociais é garantir uma existência digna por meio de um mínimo existencial, nos seguintes termos:

Os direitos sociais de cunho prestacional encontram-se a serviço da igualdade e da liberdade material, objetivando a proteção da pessoa contra as necessidades de ordem material e à garantia de uma existência com dignidade, constatação esta que tem servido para fundamentar um direito fundamental [...] a um mínimo existencial, compreendido aqui [...] não como um conjunto de prestações suficientes apenas para assegurar a existência humana, mas uma vida com dignidade no sentido de uma vida saudável como deflui do conceito de dignidade adotado nesta obra [...]. (SARLET, 2011, p. 111).

Os direitos sociais possuem um conteúdo econômico-social, com o intuito de aperfeiçoar as condições de vida e trabalho para todos, através de prestações positivas do Estado em prol dos menos favorecidos e setores economicamente mais frágeis.

Ademais, são intangíveis e irredutíveis e, portanto, qualquer ato que propenda a restringir ou aboli-los converte-se em um ato inconstitucional, emergindo, então, o princípio da proibição do retrocesso social.

Para Canotilho, este princípio garante que esses direitos sejam efetivos, de modo que qualquer medida que venha a aniquilá-los ou revogados seja inconstitucional. (CANOTILHO, 2013, p. 321). 
Em que pese não ser expresso, o princípio da proibição do retrocesso social tem aplicabilidade plena, como o direito de resistência e o princípio da dignidade da pessoa humana, se convertendo em corolário dessa dignidade.

Os direito sociais são tidos como direitos prestacionais, pois exigem do Estado prestações para sua efetividade, uma postura ativa por parte do ente estatal. Porém, consoante com Firmino, o Estado perde o controle da sua economia, prejudicando a aplicabilidade dos direitos sociais e, surgindo o poderdever de proteger um mínimo necessário a uma vida digna.

Firmino afirma que não se pode fazer uma leitura restritiva dos direitos sociais como normas programáticas:

A leitura restritiva dos direitos fundamentais resulta em notável prejuízo ao cidadão, porque este terá seu patrimônio jurídico reduzido. Isto ocorre de forma numérica, quando reduz o rol de direitos fundamentais de forma sofisticada, através do enquadramento dos direitos sociais como normas programáticas. (FIRMINO, 2013, p. 277).

Os direitos sociais fomentam um maior debate sobre sua exigibilidade judicial, isto é, sua dimensão prestacional é mais evidente, abrangendo, portanto, uma relevante dimensão econômica, pois requerem uma destinação de recursos para serem satisfeitos, de maneira que são tidos como normas programáticas, pois não são concretizados de pronto, dependendo de intervenção legislativa e administrativa para tanto.

Direitos sociais, portanto, são prestações positivas do Estado em prol dos mais necessitados e dos setores com a economia mais fraca da sociedade, dizendo respeito a algo a ser materializado, realizado. Estes direitos possuem conteúdo econômico-social, já que por meio deles se procura melhorar as condições de vida e de trabalho de todos, assim, não correspondem a uma específica categoria de titulares. São gerais e evidenciam o que condiz à pessoa humana ser e ter para que 
se tenha dignidade e, portanto, não são puramente formais, ou seja, sem conteúdo, pois a Constituição lhes confere eficácia relativa ao mínimo existencial quanto a isso.

Entretanto, as normas constitucionais relativas aos direitos sociais lhes conferem direito subjetivo em termos amplos, como é o exemplo ao ensino obrigatório e gratuito, pois podem ser exigidos em juízo, quando tratados nessa perspectiva.

Destarte, a afirmação de serem direito subjetivo não resolve de plano, os problemas, por outro lado, dizer que direitos sociais não são subjetivos, não significa que não tenham eficácia jurídica, quanto a isso explica Ledur:

E qualquer modo, se na própria Constituição ou na legislação infraconstitucional direitos sociais obtiveram ou obtêm concretização, então o que originalmente somente era direito objetivo passa a conferir, também, direitos subjetivos. (LEDUR, 2009, p. 89).

Quanto a serem direitos prestacionais, tal ideia adveio com os direitos sociais do estado social de direito, principalmente os de seguridade social e tal expressão impôs a ideia de serem deveres objetivos aos poderes estatais, se orientando à atividade maior de Estado.

Urge salientar que a relevância da dimensão objetiva advém do fato dos direitos fundamentais sociais se constituírem como cláusula pétrea.

Há uma grande divergência quanto ao fato da eficácia dos direitos sociais, pois, tendo em vista que são direitos prestacionais estes requerem políticas públicas e demais ações positivas do Estado para serem concretizados. A questão em comento está na competência constitucional para elaborar a legislação concretizadora desses direitos, em que não se reconhece poder ao judiciário, mas sim ao legislativo, o que ocasiona ainda mais morosidade para a efetivação destes. 
Assim, é que os direitos sociais, por serem prestações positivas do Estado, tem sua eficácia limitada em razão do poder-dever do ente estatal em prover tais direitos, para que se possa atingir o princípio da dignidade da pessoa humana. Entretanto, antes de se analisar sobre tal princípio, mister se fazer uma análise sobre os direitos sociais, de forma específica.

\section{DO PRINCÍPIO DA DIGNIDADE DA PESSOA HUMANA}

O princípio da dignidade da pessoa humana está assegurado e positivado no artigo $1^{\circ}$ da Constituição de 1988 , sendo a dignidade da pessoa humana declarada como um dos fundamentos da República Federativa do Brasil.

Não há, entretanto, na doutrina, um conceito preciso e único da dignidade, isto porque é uma qualidade inerente a todo ser humano, de tal forma que passara a ser definida como o valor que identifica o indivíduo como ser humano.

Quanto à dificuldade em conceituá-la, Sarlet afirma “[...] ser mais fácil desvendar o que a dignidade não é do que expressar o que ela é." (SARLET, 2011, p. 50).

Mesmo não podendo se falar em uma definição genérica e abstrata aceita de forma consensual, a doutrina e a jurisprudência procuraram estabelecer alguns contornos basilares acerca da dignidade.

Todavia, Sarlet procura seguir argumentos que contribuam para uma definição não arbitrária, porém apta a se concretizar no âmbito jurídico, retomando a ideia do pensamento clássico, qual seja a de que a Dignidade é uma qualidade intrínseca da pessoa humana, irrenunciável e inalienável, sendo um elemento que qualifica o ser humano como tal, não se podendo ponderar na possibilidade de uma pessoa ser titular de uma pretensão a que a dignidade lhe seja concedida. (SARLET, 2011, p. 51). 
Para o mesmo autor, a dignidade pode e deve ser reconhecida, respeitada, promovida e protegida, entretanto, não pode ser criada, concedida ou retirada, em que pese ser atribuída a cada ser humano de forma inerente.

Em face disso, a dignidade independe das circunstâncias concretas, sendo todos iguais em dignidade "[...] no sentido de serem reconhecidos como pessoas." (SARLET, 2011, p. 54), mesmo que não se portem de forma igualmente digna nas relações com os outros e consigo mesmos.

Isto posto, tanto pelo fato de ser inerente à natureza humana, quanto pelo fato de expressar o seu valor absoluto, é que a dignidade não poderá ser desconsiderada, mesmo quanto às pessoas que cometem ações indignas e infames.

À vista disso e do que dispõe a Declaração Universal da Organização das Nações Unidas, tem-se que o elemento nuclear da noção da dignidade da pessoa humana continua sendo reconduzido e centralizado na autonomia e no direito de autodeterminação da pessoa.

Canotilho tem o mesmo entendimento, se referindo que o principal material que se subjaz à noção de dignidade da pessoa humana se consolida "[...] no princípio antrópico que acolhe a ideia pré-moderna e moderna da dignitas-hominis, ou seja, do indivíduo conformador de si próprio e da sua vida segundo o seu próprio projeto espiritual." (CANOTILHO, 2004, p. 219).

Tem-se, então, que a liberdade, o reconhecimento e a garantia de direitos de liberdade, se constituem uma das principais exigências da dignidade da pessoa humana.

A dignidade é entendida como limite e tarefa dos poderes estatais e da comunidade em geral, sendo uma dimensão defensiva e prestacional deste princípio.

De tal sorte, como limite das ações do Poder Público, a 
dignidade é algo pertencente a cada um, não podendo ser alienado ou perdido. E como tarefa, entende-se que a dignidade requer que o Estado guie as suas ações, no sentido de preservar a que já existe, bem como promovendo-a, por meio da elaboração de condições que oportunizam o pleno exercício e fruição da dignidade.

Assim, a dignidade depende da ordem comunitária, pois se averigua até qual ponto o indivíduo consegue realizar sozinho as suas necessidades existenciais básicas.

É encontrada explicitações da dignidade da pessoa humana nos direitos fundamentais, sendo que em cada um deste há algum conteúdo daquela. Entretanto, nem todos os direitos fundamentais possuem seu fundamento direto no princípio da dignidade da pessoa humana, em que pese a eficácia e a inviolabilidade desta encontrarem relação e dependência da capacidade de se integrar aos direitos fundamentais.

Porém, ao verificar os direitos sociais é perceptível que eles são uma parte dos direitos fundamentais e possuem o fundamento no princípio da dignidade da pessoa humana.

A dignidade da pessoa humana, sendo um valor, exige o reconhecimento e proteção dos direitos fundamentais, já que as pessoas são titulares de direitos humanos em razão da sua dignidade, e esses direitos buscam uma existência digna.

Tanto os direitos fundamentais, quanto o direito de igualdade estão diretamente baseado na dignidade da pessoa humana, em que pese a Declaração Universal dos Direitos Humanos da Organização das Nações Unidas consagrar que todos os seres humanos são iguais em dignidade e direitos, no artigo $1^{\circ}$.

Também quanto à Declaração Universal dos Direitos Humanos, que em seu preâmbulo alude que o reconhecimento da dignidade é inerente a todos e constitui o fundamento da liberdade, da justiça e da paz no mundo. 
Portanto, o pressuposto essencial para que a dignidade da pessoa humana seja respeitada é a garantia da isonomia de todos os seres humanos, não se admitindo tratamentos discriminatórios e arbitrários, como a escravidão, por exemplo, ademais de englobar o respeito e proteção da integridade física e emocional da própria pessoa.

Conforme o próprio preâmbulo da Declaração Universal dos Direitos Humanos já alude, as necessidades humanas básicas reúnem as liberdades e os direitos sociais, abrangendo a dignidade da pessoa humana.

$\mathrm{O}$ vínculo da dignidade com o direito à saúde, por exemplo, é indissociável, já que para a garantia desse direito o princípio da dignidade da pessoa humana deve ser utilizado como fundamentação.

Nesse sentido, é perceptível que a dignidade da pessoa humana não existirá sem um conteúdo mínimo imprescindível de direitos fundamentais sociais para a sua existência, pois são pressupostos para que a dignidade exista.

A dignidade é critério substantivo na ocorrência de conflitos principiológicos, sendo tomada como princípio estruturante do Estado Constitucional, enquanto que a proporcionalidade é tida como princípio mediador, já que é utilizada na ponderação como um norte para a solução dos conflitos, pois deve ser adotada a que mais se aproxime da dignidade da pessoa humana, justamente pelo seu conteúdo axiológico e ser razão de existir do Estado.

Isto porque, os métodos mais clássicos para a solução de conflitos de regras (o hierárquico, cronológico e da especialidade) não são suficientes para a resolução dos conflitos, sendo necessária, então, a ponderação e a dignidade.

A ponderação de interesses é mais um método utilizado 
para a solução de conflitos de princípios, não podendo mitigar a dignidade da pessoa humana em sua essencialidade.

Portanto, os valores inerentes à dignidade da pessoa humana, como a igualdade e liberdade, nortearão no aspecto substantivo a ponderação de interesses, ponderando os três elementos que se decompõe o fenômeno jurídico: fato, valor e norma; possuindo o princípio da proporcionalidade como critério mediador.

Todavia, a ponderação de interesses só será necessária quando for caracterizada a colisão entre princípios constitucionais no caso concreto.

Quando ocorrerem limites aos direitos sociais, o princípio da dignidade da pessoa humana tem função de proteção, em que pese não existir direito absoluto. Há, portanto, restrições à atividade limitadora destes para evitar o esvaziamento e a supressão de tais direitos.

Ademais, em princípio, não pode haver nenhuma restrição de direito que seja desproporcional ou que afete o seu núcleo essencial.

Em relação a isto, a dignidade da pessoa humana é de extrema relevância, já que se constitui, para muitos doutrinadores, o núcleo essencial dos direitos, operando como "limite dos limites" destes. (SARLET, 2011, p. 143).

Ingo Sarlet argumenta que nem todos os direitos fundamentais possuem um conteúdo em dignidade, entretanto, todos possuem um núcleo essencial, ao menos no aspecto de uma proibição de abolição do poder reformador ou de uma vedação de restrição que afete os aspectos nucleares do direito em causa. (SARLET, 2011, p. 143).

Destarte, qualquer violação de um direito social corresponde, necessariamente, a uma violação da dignidade da pessoa humana, não implicando a violação do conteúdo em dignidade 
que o direito fundamental que fora atingido possa ter.

A dignidade se constitui em um dos critérios materiais para a aferição de incidência de uma proibição de retrocesso dos direitos fundamentais.

Assim, é que medidas supressivas ou restritivas de prestações sociais implantadas pelo legislador serão consideradas inconstitucionais por violação do princípio da proibição do retrocesso, sempre que afetar o núcleo essencial dos direitos sociais e resultar em uma pretensão da dignidade da pessoa humana.

Portanto, o princípio da dignidade da pessoa humana serve como elemento de proteção dos direitos contra medidas restritivas e o uso abusivo de direitos, bem como justificativa para imposição de restrições aos direitos fundamentais, atuando como elemento limitador.

A dignidade da pessoa humana é um valor, tendo em vista ter suas raízes na ética e na filosofia moral, sendo vinculada à moralidade, ao bem, à conduta correta e à vida boa.

Em sendo princípio e valor fundamental, pela dignidade é conferida unidade de sentido e legitimidade à ordem constitucional, sendo um elemento informador de direitos e garantias fundamentais, mesmo que nem todos os direitos fundamentais possam ser reconduzidos diretamente ao princípio da dignidade da pessoa humana.

Desse modo é também um elemento de proteção dos direitos fundamentais contra medidas restritivas, exercendo função instrumental hermenêutica de todo o ordenamento jurídico.

Barroso afirma que a dignidade é um valor fundamental, mas que não deve ser tido como absoluta, classificando-a como um princípio jurídico com status constitucional e não como direito autônomo. (BARROSO, 2014, p. 64).

Desta forma, em sendo um valor fundamental que tam- 
bém é um princípio constitucional, a dignidade é tida como justificação moral e fundamento jurídico-normativo dos direitos fundamentais.

A dignidade tem como papel ser uma fonte de direitos e deveres, mesmo daqueles não expressos, sendo extraídos do significado essencial da dignidade.

Assim, a dignidade da pessoa humana deverá, sempre que possível, prevalecer sobre outros princípios, entretanto, ainda não se tem uma doutrina majoritária acerca da sua natureza jurídica.

\section{DA EFETIVAÇÃO DO PRINCÍPIO DA DIGNIDADE DA PESSOA HUMANA ATRAVÉS DAS POLÍTICAS PÚBLICAS}

Antes de se tratar mais especificamente sobre políticas públicas dos direitos sociais, mister se fazer uma correlação entre o princípio do mínimo existencial e seu contraponto, o princípio da reserva do possível, já que são limites aos direitos sociais, e, portanto, à dignidade da pessoa humana.

O mínimo existencial representa o limite ao atendimento dos direitos sociais pelo Estado, já que se relaciona com o problema da concretização desses, bem como é ligado de forma intrínseca ao princípio da dignidade da pessoa humana.

Ralws trata da garantia do mínimo social como pressuposto para o exercício da liberdade. (GONÇALVES, 2013, p.178). De tal sorte que a Constituição Federal de 1988 estabeleceu direitos fundamentais sociais ante a concepção das necessidades humanas básicas e não apenas por meio do conceito de mínimo social.

Desse modo, a Constituição de 1988 privilegiou a soberania popular, bem como a participação da sociedade na gestão das políticas públicas, obrigando, assim, ao Estado garantir as 
necessidades humanas básicas.

O mínimo existencial, portanto, possui uma vertente garantista e outra prestacional. A primeira busca impedir a violação do direito, cedendo de outros direitos ou deveres ante a garantia de meios de que as mínimas condições de vida digna se satisfaçam.Já a vertente prestacional tem um caráter de direito social, exigível frente ao Estado, exigindo obrigações deste.

Nesse sentido, é perceptível que alguns direitos fundamentais que necessitam da garantia do mínimo existencial, sendo essenciais, são atinentes à dignidade da pessoa humana. Assim, Sarmento define como sendo um conteúdo que é exigido dos direitos fundamentais sociais e núcleo irredutível do princípio da dignidade da pessoa humana, "[...] composta por quatro elementos essenciais: educação fundamental, saúde física, assistência aos desamparados e acesso à justiça." (SARMENTO, 2014, p.150).

De tal sorte, que com isso o Poder Judiciário deve estar apto para efetivar esses direitos sempre que o Poder Executivo ou Legislativo se mostrarem ineficazes, assumindo um caráter subjetivo,através da judicialização.

Cláudia Gonçalves elenca os conteúdos que devem compor os direitos fundamentais sociais, como por exemplo: a saúde preventiva e curativa (artigo $6^{\circ}$ e artigo 196, Constituição Federal); a educação básica obrigatória e gratuita dos quatro aos dezessete anos de idade (artigo 208, I, Constituição Federal); educação básica especializada às pessoas portadoras de deficiência (artigo 208, III, Constituição Federal); previdência social (artigo $6^{\circ}$, Constituição Federal), entre outros (GONÇALVES, 2013, p.188).

Assim, o mínimo existencial é tido como um conjunto de situações materiais que são indispensáveis a uma existência humana digna. 
Com isso, para que o princípio da dignidade da pessoa humana se efetive, o estado deve prover o mínimo social e para que seja garantida a todas as pessoas uma existência digna.

Em um confronto entre o princípio da reserva do possível e do mínimo existencial, Cláudia Gonçalves afirma que os valores de ordem econômica não são absolutos, não podendo ficar acima da efetivação dos direitos sociais, mesmo sendo parte na ponderação do caso.

Ao tratar de direitos fundamentais sociais não há como não falar da teoria da reserva do possível, pois em sendo direitos prestacionais, necessitam "[...] encontrar limites na riqueza nacional ou na situação econômica do país.” (SILVA, 2011, p.183)

Isto porque os recursos públicos não são inesgotáveis, e mesmo as necessidades sociais não são todas atendidas. De tal sorte, se revela a incidência da teoria da reserva do possível, pois os direitos sociais somente serão efetivados de acordo com as condições da riqueza nacional.

O Estado baseia-se na limitação orçamentária para o não atendimento de algumas necessidades, ou seja, como forma de limitação ao dever prestacional, atingindo diretamente os direitos fundamentais positivados constitucionalmente.

Dessa forma, Sarmento trata o instituto da reserva do possível como um " $[\ldots]$ controle do erário público no interesse maior da sociedade." (SARMENTO, 2014, p. 161), resguardando o mínimo existencial em termos do princípio da dignidade da pessoa humana, de tal sorte que este princípio traduzido no mínimo existencial a uma vida digna tornou-se o limite onde o princípio da reserva do possível poderá ser exarado como fundamentação.

Entretanto, o princípio da reserva do possível não pode ser sempre utilizado pelo Estado para não cumprir com a sua obrigação, afirmando não haver recursos disponíveis, pois o Estado deve cumprir com o mínimo existencial, condizente com o 
princípio da dignidade da pessoa humana.

Todavia, o mínimo existencial é capaz de conviver de forma harmônica com a reserva do possível, se for associado ao estabelecimento de prioridades orçamentárias.

De tal sorte que em não se realizando os efeitos contidos no mínimo existencial, se viola o princípio da dignidade da pessoa humana, que também poderá ser violado com a não efetivação de políticas públicas relacionadas aos direitos sociais.

As políticas públicas, então, podem ser definidas de acordo com o ramo do conhecimento que esteja estudando-as, correspondendo a direitos assegurados constitucionalmente ou afirmados pelo reconhecimento da sociedade ou poderes públicos.

Ao se afirmar de forma genérica que as políticas públicas estão a cargo da Administração Pública, sem interferência do Poder Judiciário, tem-se que "[...] tudo que se puder subsumir ao conceito estará sujeito à ampla discricionariedade administrativa." (FONTE, 2015, p.35).

O controle das políticas públicas ainda persiste na esfera dos tribunais, com alguns dos seguintes temas discutidos:

Direito à saúde, com a concessão de tratamentos médicos, entrega de medicamentos, mantimentos, próteses e saneamento básico, e direito à educação, com a construção de escolas, vagas nas escolas, transporte ao colégio e provimento de professores [...]. (FONTE, 2015, p. 44-45).

Francisco E. Heidemanm define Política Pública "[...] como a função básica do governo e de seu aparato organizacional." (HEIDMANN, 2014, p.34), sendo que esta cobra do governo maior preocupação com eficácia econômica e social do que com o efetivo exercício do poder político.

Desta forma, é perceptível que as políticas públicas são meios para a efetivação de direitos de cunho prestacional pelo 
Estado, não obstante a sua relevância para a efetivação de direitos não fundamentais.

Esta concepção permite reconhecer nos direitos sociais e nos demais direitos fundamentais o objetivo central de algumas das políticas públicas, entretanto, não há uma definição exata do que são políticas públicas, mas pode-se dizer de forma resumida que são programas de ação do governo.

Já Eros Roberto Grau, traduz as políticas públicas como "[...] todas as atuações do Estado cobrindo todas as formas de intervenção do Poder Público na vida social." (GRAU, 2011, p. 28), de tal sorte, que o autor conclui que o direito também é uma política pública.

É relevante se discutir política pública porque o Estado não possui recursos ilimitados e estes devem ser utilizados de forma a atenderem a grande demanda da sociedade e, para tanto, necessitando de um mínimo de planejamento de onde atuar.

A tarefa prioritária, portanto, das políticas públicas é atender primeiro os setores marginalizados da sociedade e, posteriormente, as que já estão operando com certa dignidade.

Nesse sentido, quem analisa a prioridade é o Poder Público, com a sua discricionariedade, entretanto, se faz mister ressaltar que essa discricionariedade deve ser acompanhada pela sociedade, além disso, tal atividade deve se pautar nos princípios da legalidade, razoabilidade e proporcionalidade, corolários da boa governança e da Administração Pública.

É cediço que os direitos sociais são realmente difíceis de conseguir efetividade, pelo seu alto custo de prestação, precisando de organização, estrutura e um grande aporte financeiro e maior atenção por parte do Estado. Nesse sentido, a norma eficaz que trate desses direitos, portanto, é aquela que possui todos os elementos normativos para a produção de efeitos, que 
por isso depende de regulamentação, principalmente quando se tratar de direitos prestacionais.

Para uma digna prestação do direito à educação, por exemplo, é necessária a construção de escolas, contratação de professores qualificados para prestarem um ensino público de qualidade, além de verba para alimentação e aquisição de materiais.

No Brasil, o Programa Bolsa Família, por exemplo, tem auxiliado a que estudantes permaneçam na escola, bem como fomentado políticas públicas direcionadas à redução de competência e as que buscam uma melhora no salário de professores, como o Fundo de Manutenção e Desenvolvimento do Ensino Fundamental e Valorização do Magistério, além de Leis específicas como a Lei de Diretrizes e Bases de Educação.

Em caso do Estado alegar a reserva do possível para o não oferecimento de educação básica gratuita, é relevante salientar que a Constituição Federal garante a destinação de receitas oriundas de impostos para a manutenção e desenvolvimento deste direito, em dezoito por cento em âmbito federal e vinte e cinco por cento no âmbito estadual e municipal, garantindo meios que propiciarão a busca de conhecimentos, com o consequente crescimento pessoal e profissional, se garantirá o princípio da dignidade da pessoa humana, como se pode ver pelo excerto abaixo:

Compreende-se o direito à educação, em face do expendido, como corolário do direito à dignidade da pessoa humana, no espectro de direito ao pleno e livre desenvolvimento de sua autonomia, com a garantia de meios que propiciarão a busca do conhecimento indispensável ao seu crescimento pessoal, possibilitando a sua efetiva interação com a comunidade como um ser pensante e atuante. (PORT, 2005, p.116).

De tal sorte, que a reserva do possível não pode ser fundamento para a ausência de prestação jurisdicional, já que se deve assegurar o mínimo existencial, em sendo o direito à edu- 
cação um direito subjetivo, inerente à pessoa humana e decorrente do princípio da dignidade da pessoa humana.

O direito social à saúde, por outro lado, é caracterizado como norma de eficácia limitada, mas quando carente da atuação estatal, ou seja, sem a devida verba orçamentária para construir, manter e melhorar os hospitais, comprar equipamentos, contratar médicos e adquirir medicamentos, não garante então o princípio da dignidade da pessoa humana. Dito isto, é perceptível o quão relevante é a política pública do Sistema Único de Saúde.

Assim, o Sistema Único de Saúde representa uma grande evolução entre as políticas públicas sociais instituídas pela Constituição Federal de 1988, e que se encontra positivado de forma infraconstitucional na Lei 8.080, de 19 de setembro de 1990 e Lei 8.142 , de 28 de dezembro de 1990, voltado para atender a toda população, tendo como diretrizes organizativas a descentralização, com apenas um comando em cada esfera governamental; a integralidade do atendimento e a participação da comunidade.

De tal sorte, que em sendo o Sistema Único de Saúde uma política pública, que atende a toda população, gratuitamente, o princípio da dignidade da pessoa humana é efetivado, através da efetivação do direito social à saúde com o atendimento médico universal e gratuito.

Isto posto, é perceptível que as políticas públicas são instrumentos adequados para a concretização dos direitos sociais, e consequentemente, da dignidade da pessoa humana, pois tornam efetivos estes direitos para os cidadãos, através de prestações do Estado.

\section{CONCLUSÃO}

O presente artigo teve como objeto a efetividade do princípio da dignidade da pessoa humana, através de políticas públicas na 
área de direitos sociais, o objetivo foi o de analisar se o princípio da dignidade da pessoa humana está sendo efetivado com a implantação de políticas públicas relacionadas aos direitos sociais.

O trabalho foi dividido em três tópicos, no primeiro estudou-se que os direitos sociais são os que mais demandam uma atuação positiva do Estado, haja vista serem direitos prestacionais, sendo, portanto, imprescindíveis para o pleno gozo de outros direitos dos seres humanos. Esses direitos possuem um conteúdo econômico-social, visando o aperfeiçoamento das condições de vida e trabalho de todos, através de prestações positivas do Estado, entre elas as políticas públicas.

No segundo tópico, tratou-se do princípio da dignidade da pessoa humana, abordando o seu conceito, sendo que é um dos fundamentos da Constituição de 1988, positivado no artigo $1^{\circ}$. Dessa forma, este princípio é tido como o valor que identifica o indivíduo como ser humano, sendo uma qualidade intrínseca, irrenunciável e inalienável da pessoa humana, pela qual o Estado deve guiar as suas ações para preservar a dignidade que já existe e promovê-la, através da elaboração de condições que oportunizam o seu pleno exercício.

Por fim, foi analisada a forma como o princípio da dignidade da pessoa humana pode ser efetivado por meio dos direitos sociais, discorrendo-se sobre o conceito de mínimo existencial daqueles, sendo este um conteúdo exigido dos direitos sociais e núcleo irredutível do princípio da dignidade da pessoa humana, haja vista que os direitos sociais em sendo prestacionais necessitam encontrar limites no orçamento público, e por isso, o Estado muitas vezes faz uso da reserva do possível alegando a impossibilidade de concretização de alguns direitos sociais.

Tratou-se sobre as políticas públicas, como sendo as atuações do Estado como formas de efetivar os direitos sociais e consequentemente o princípio da dignidade da pessoa huma- 
na, cobrindo as formas de intervenção do Poder Público na vida social.

Entende-se, então, que as políticas públicas serão instrumentos adequados para concretizar os direitos sociais no Brasil, pois se entende que os direitos sociais, em sendo prestacionais, necessitam de atuação positiva do Estado, a qual se concretiza através de políticas públicas de direitos sociais para a sociedade, como por exemplo o Sistema Único de Saúde. Urge salientar que não se analisou neste trabalho o resultado e a forma em que as políticas públicas são elaboradas, mas se os direitos sociais, quando efetivados, concretizam ou não a dignidade humana.

Assim, os direitos sociais quando concretizados, efetivam a dignidade humana, pois a dignidade da pessoa humana é um valor, sobre o qual se identifica o indivíduo como tal. Por outro lado, se efetivado os direitos sociais, se estará efetivando a dignidade da pessoa humana.

Observa-se finalmente que o presente trabalho não teve a intenção de esgotar o assunto, mas sim de contribuir para a discussão sobre o tema das políticas públicas, dos direitos sociais e da dignidade da pessoa humana.

\section{REFERÊNCIAS}

BARROSO, Luís Roberto. A dignidade da pessoa humana no direito constitucional contemporâneo: a construção de um conceito jurídico à luz da jurisprudência mundial. 3. ed. Belo Horizonte: Fórum, 2014.

BONAVIDES. Paulo. Curso de direito constitucional. 26. ed. São Paulo: PC Editorial Ltda, 2012.

BRASIL, Constituição da República Federativa do Brasil de 1988. Brasília: Senado Federal, 2017.

CANOTILHO, J.J. Gomes. ET AL. Comentários à Constituição do Brasil. São Paulo: Saraiva/Almediana, 2013.

CORDEIRO, Karine da Silva. Direitos fundamentais sociais: dignidade da pessoa humana e mínimo existencial: o papel do poder judiciário. Porto Alegre: Livraria do Advogado Editora, 2012. 
DIAS. Reinaldo; MATOS, Fernanda. Politicas públicas: princípios, propósitos e processos. São Paulo: Atlas, 2012.

FIGUEIREDO, Mariana Filchtiner. Direito fundamental à saúde: parâmetros para sua eficácia e efetividade. Porto Alegre: Livraria do Advogado Editora, 2007.

FIRMINO. Nelson Flávio. Curso de direitos fundamentais. Curitiba. Juruá. 2013.

FONTE, Felipe de Melo. Políticas públicas e direitos fundamentais. 2. ed. São Paulo: Saraiva. 2015.

GONÇALVES, Cláudia Maria da Costa. Direitos fundamentais sociais: releitura de uma constituição dirigente. 3. ed. Curitiba: Juruá, 2013.

GONÇALVES, Flavio de Oliveira; FRANÇA, Marco Tulio Aniceto. Qualidade educacional nos municipios nordestinos: evidências a partir do prova Brasil. 2005.

GRAU, Eros Roberto. O direito posto e o direito pressuposto. 8. ed. São Paulo: Malheiros Editores LTDA. 2011.

HEIDMANN, Francisco G. SALM, José Francisco. Política pública e desenvolvimento: bases epistemológicas e modelos de análise. 3. ed. Brasília: Editora Universidade de Brasília, 2014.

LEDUR. José Felipe. Direitos fundamentais sociais: efetivação no âmbito da democracia participativa. Porto Alegre: Livraria do Advogado Editora, 2009.

ONU. Declaração universal dos direitos do homem. Disponível em: http://www.ohchr. org/EN/UDHR/Pages/Language.aspx?LangID=por. Acesso em: 12 jul. 2017.

PASOLD, Cesar Luiz. Metodologia da pesquisa jurídica: teoria e prática. 13. ed. Florianópolis: Conceito Editorial, 2015.

PINHO. Rodrigo César Rebello. Teoria geral da constituição e direitos fundamentais. 8. ed. São Paulo: Saraiva. 2008.

PISARELLO, Gerardo. Los derechos sociales y sus garantías: elementos para una reconstrucción. Madrid: Editorial Trotta, 2007.

PORT, Otávio Henrique Martins. Os direitos sociais e econômicos. São Paulo: RCS Editora. 2005.

SARLET, Ingo Wolfgang. Dignidade da pessoa humana e direitos fundamentais na Constituição Federal de 1988. 9. ed. Porto Alegre: Livraria do Advogado, 2011.

SARMENTO, Leonardo. A efetividade dos direitos fundamentais e a eficácia das politicas públicas. Rio de Janeiro: Editora Multifoco. 2014.

SILVA, José Afonso. Curso de direito constitucional positivo. 36. ed. São Paulo: Malheiros Editores. 2013.

SILVA, Sandoval Alves. Direitos sociais: leis orçamentárias como instrumento de implementação. Curitiba: Juruá. 2011. 